\title{
Fighting in the Corner of Children in Low Income Countries
}

\author{
S Mzezewa* \\ Department of Plastic and Reconstructive Surgery, University of Limpopo, South Africa \\ *Corresponding Author: S Mzezewa, Department of Plastic and Reconstructive Surgery, University of Limpopo, South Africa.
}

Received: September 24, 2019; Published: October 11, 2019

With an hour to go before Mrs Nkomo (the employer) comes home from work and Mr. Nkomo, the civil servant husband, passes through the preschool picking up the four-year old son, the maid, (the domestic worker and baby minder), has to finish up the cooking and other house hold chores including bathing the ten-month old baby. The maids generally don't have any training for their work and many do not live with the employing family.

The day was chilly, the maid decided she would need hot water to bath the baby. She opened sufficient hot water into the bath tub, without adding cold water the maid lowered the baby into the hot water resulting in a loud scream from the baby due to scald burns of the buttocks and perineum. Realising the injury from the screaming baby, she called the neighbouring mother for help, together they took the baby to a clinic which is within walking distance. The neighbouring mother then phoned Mrs Nkomo to inform her of injury to her baby. After first aid at the clinic the baby was transferred to a Burns unit for definitive care.

If your hands are comfortable in the baby`s bath water, the baby is likely to be comfortable in it. This should be some of the message imparted to young parents and any 'would be' baby minders. Majority of burn injuries in Low Income countries happen to children in the home environment. Compounding the problem is working parents who have to surrender the care of their young children to the care of untrained baby minders, most of whom are young and without children.

On the other hand, a young woman gives birth to a complete cleft lip and palate baby. She is shocked because this is the first time she has ever seen a baby with this condition. The clinic staff are equally shocked, but are able to transfer the mother and baby to a central hospital. At the central hospital, a naso-gastric tube is inserted for feeding the baby, who is further transferred to a central hospital that has a plastic surgery department. Up to this point, the mother has not been counselled about the condition of the baby nor has she been assisted with the breast feeding-technic of the cleft lip/palate baby.
This mother is actually afraid of the baby, this is not the baby that the mother was idealising and expecting during her pregnancy. At $25 \mathrm{~cm}$ from the mother`s face, the infant can read and interpret the mother's facial expression of love or lack of it. Childmaternal bonding either happens or fails at this stage. In some environments, the mother is accused of witchcraft, infidelity during pregnancy and the husband is advised by his relatives to divorce her. This may lead to depression of mothers who give birth to babies with cleft lip/palate.

At definitive tertiary hospitals, the mother is told that the baby will be operated at the age of three months. Meanwhile she should feed the baby using a special feeding bottle. These bottles are expensive and not available at public hospitals, often times have to be imported. Even if they were available, these mothers are usually from the low-income bracket, living in houses that do not have running water. This feeding technique will inevitably result in fatal gastro enteritis. Moreover, how does a mother who is afraid of the baby be expected to nurse him/her for three months?

Although waiting for three months before cleft lip repair is acceptable in environments with cleft lip/palate support-groups and counselling services, in low income countries, it is not the best option. The likelihood of these babies dying from malnutrition and/ or gastroenteritis during the waiting period of three months is very high.

Neonatal cleft lip repair (Neonatalcheiloplasty), should be recommended when the skill is available. The training of plastic surgeons in low income countries should include neonatal cheiloplasty and counselling for the sake of the mother and the baby.

In summary: Baby minders should have some training in taking care of young children as this may reduce the accidents that occur under their care. Cleft lip babies should be operated in the neonatal period to encourage bonding. Cleft lip mothers should be counselled as soon as possible to prevent depression and poor 
baby maternal bonding. Education of Family and society emphasis-

ing that cleft lifts/palates are operably like other birth anomalies, needs to be promoted.

\section{Volume 2 Issue 11 November 2019}

(C) All rights are reserved by $S$ Mzezewa. 